MISES: Revista Interdisciplinar de Filosofia, Direito e Economia ISSN 2318-0811

Volume IV, Número 1 (Edição 7) Janeiro-Junho 2016: 141-150

\title{
O Que a Medicina Soviética Nos Ensina
}

\author{
Yuri Maltsev **
}

Resumo:A partir de sua experiência pessoal e de relatos históricos, o autor apresenta um panorama da medicina soviética e discute as possíveis implicações da implementação de sistemas de saúde socializados, tais como as propostas do ObamaCare.

Palavras-Chave: Saúde pública. União Soviética. Medicina socializada.

\section{Lessons from Soviet Medicine}

\begin{abstract}
From his personal experience and historical accounts, the author presents a general outlook of Soviet medicine and discusses the possible implications of implementing socialized health systems, such as the proposals of ObamaCare.
\end{abstract}

Keywords: Public health. Soviet Union. Socialized medicine.

Classificação JEL: I18.

* Publicado originalmente em: Journal of American Physicians and Surgeons, Vol. 16, No. 2 (Summer 2011): 47-51. Traduzido do inglês para o português por Claudio A. Téllez-Zepeda.

** Yuri Maltsev, Ph.D., é professor de economia no Carthage College em Wisconsin. Antes de fugir da União Soviética para os Estados Unidos da América em 1989, foi membro de uma equipe sênior de economia soviética que trabalhou no pacote de reformas do presidente Gorbachev sob a Perestroika. É senior fellow do Mises Institute e recebeu o prêmio Luminary Award da Free Market Foundation.

E-mail: ymaltsev@carthage.edu 


\section{I - INTRODUÇÃO}

Após a Revolução Socialista na Rússia, em 1917, formou-se a União das Repúblicas Socialistas Soviéticas. A economia foi socializada à força, inclusive a medicina e os setores correlatos. O Estado controlava tudo, dizendo que seu controle era para o benefício de todos e que haveria cobertura de saúde universal, com um "direito constitucional à saúde" para todos os cidadãos soviéticos.

Os altos funcionários da elite do Partido Comunista anunciavam que todos teriam acesso aos serviços de saúde e que o sistema eliminaria o "desperdício" decorrente daquilo que Vladimir Lenin (1870-1924) chamava de "duplicação e paralelismo desnecessários"; ou seja, a competição no mercado. Tal como ocorre com nosso governo atual, os funcionários do Partido Comunista e seus servidores intelectuais consideraram conveniente eximir-se do sistema médico igualitário que criaram e controlavam, deixando-o para as massas cinzentas, enquanto proporcionavam a si mesmos um sistema médico de excelência para acompanhar suas posições sociais de elite. Enquanto os cidadãos soviéticos comuns, "trabalhadores e camponeses" aos olhos de seus mestres, morriam nos hospitais gerenciados pelo Estado, os equipamentos e medicamentos que poderiam ter salvo suas vidas se encontravam nas instalações da elite governante, distantes do alcance dos cidadãos ordinários.

A irresponsabilidade socialista ignorou o fato de que ninguém se esforça sem esperar recompensa. $\mathrm{O}$ resultado disso é ilustrado no ditado russo daquela época: "Fingem que nos pagam e fingimos que trabalhamos". A apatia decorrente da falta de qualquer incentivo para buscar a excelência paralisou a economia socialista, inclusive a medicina, produzindo como resultado cuidados médicos e outros serviços de péssima qualidade, corrupção disseminada e perda massiva de vidas.

Oódio e a inveja perpetuados pelas ideias marxistas, que pressupõem que aqueles que se saem melhor que os demais são os causadores da miséria dos mais pobres, significava que os médicos supostamente deviam por sua educação à benevolência do Estado e, portanto, deveriam receber salários tais como o de um amigo pessoal, que recebia um terço do salário de um motorista de ônibus sob o sistema soviético (quando era considerado um escravo público descartável), enquanto na Rússia de hoje é um neurocirurgião próspero e famoso.

O sistema contou com várias décadas para operar em mais de trinta países socialistas, da Rússia ao Vietnã, de Cuba a Angola, lugares nos quais o tratamento das pessoas como escravos públicos descartáveis por parte de seus senhores socialistas (o que ocorreu inclusive com aqueles destinados ao setor da medicina) paralisou as economias socialistas.

\section{II - Uma Agenda Mortal Encoberta no Ocidente}

A maior parte dos historiadores ocidentais acreditava que o terror de Joseph Stalin (1878-1953) ocorreu contra opositores políticos. Entretanto, os grandes expurgos foram, na realidade, um ataque contra as pessoas comuns. Mais da metade de todas as execuções foi levada a cabo nas zonas rurais. A liquidação dos fazendeiros independentes enviou dez milhões (inclusive três milhões de crianças) para a Sibéria, onde a maioria morreu. Somente na Ucrânia, Stalin matou de fome mais de sete milhões de camponeses. Por volta da primavera de 1933, a estimativa é que 25.000 pessoas morriam por dia na Ucrânia, sendo que um terço delas eram crianças. Líderes socialistas sedentos de sangue deportaram pessoas doentes e deficientes físicos, bem como mães solteiras e suas crianças, que não representavam ameaça alguma ao governo. As autoridades tinham uma agenda diferente, que incluía eliminar as pessoas que poderiam ter que curar e alimentar. O número de pessoas assassinadas 
por seus líderes socialistas se eleva a 262.000.000, de acordo com o demógrafo norte-americano Rudolph Joseph Rummel (1931-2014) ${ }^{1}$. O socialismo se tornou a doença mais mortal de nosso tempo.

Por que isto não é de conhecimento comum? Uma razão é a radiofusão com financiamento público: a National Public Radio [Rádio Pública Nacional] (NPR) e o Public Broadcasting System [Sistema de Radiofusão Pública] (PBS). De sua programação, parece que os heróis do presente e do passado para a NPR incluem Stalin, Mao Tsé-Tung (18931976), Salvador Allende (1908-1973), Fidel Castro (1926-2016), Hugo Chávez (1954-2013), Yasser Arafat (1929-2004), o grupo Hezbollah, o arcebispo Desmond Tutu, Vladimir Putin e a Irmandade Muçulmana. A NPR e o PBS envenenam o ar com propaganda descarada contra o livre mercado e glorificam a escravidão pública aqui e no exterior. A servidão decerto "reduziu os custos" da mão-de-obra, "eliminou o desperdício" da negociação salarial e evitou a "duplicação e paralelismo desnecessários". A despeito das promessas de diversos republicanos proeminentes, desde o presidente Ronald Reagan (1911-2004) até John Boehner (R-Ohio), presidente da Câmara dos Representantes dos Estados Unidos, os contribuintes ainda são forçados a financiar essas entidades, desafiando abertamente a Constituição dos Estados Unidos da América. Ironicamente, a maior parte dos ouvintes da NPR e telespectadores da PBS são pessoas de renda elevada, intelectuais e profissionais brancos. Por que todos deveriam financiar as preferências de rádio e televisão da elite intelectual deste país, aqueles que desfrutam dos maiores rendimentos do mundo como pessoas do ramo de entretenimento, advogados, professores universitários, dirigentes sindicais públicos, políticos, burocratas e diversos outros privilegiados?

${ }^{1}$ RUMMEL, R. J. 20th Century Democide. In: Freedom, Democracy, Peace, Poder, Democide, and War. Disponível em: <www.hawaii.edu/powerkills/20th. htm>.

\section{III - Experiência Pessoal no Sistema SOVIÉTICO}

No papel, o sistema soviético pode parecer bom. O governo soviético empregou indicadores para os planos implementados, semelhantes à lei "Que Nenhuma Criança Fique Para Trás" nos Estados Unidos da América, para mensurar o desempenho dos hospitais, sendo a redução da taxa de mortalidade vista como o melhoramento mais desejado e facilmente mensurado. Para atingir as metas do plano e melhorar as estatísticas sobre a quantidade de pessoas morrendo dentro do sistema, os pacientes eram rotineiramente empurrados porta afora antes de darem seu último suspiro.

Na realidade, na maior parte das vezes os pacientes precisavam pagar propinas para receber atenção dos médicos e do pessoal de enfermagem. A anestesia geralmente "não estava disponível" para abortos e pequenas cirurgias, a não ser que o paciente pudesse pagar um suborno.

Nasci e fui criado em uma família de várias gerações de profissionais da Medicina. Meus pais e minha irmã ficaram consternados com suas breves experiências como praticantes da Medicina e se transferiram para a área de pesquisas médicas, tornandose muito bem-sucedidos em suas áreas de investigação. Meu pai Nikolai se tornou um biofísico famoso, minha mãe Olga se tornou bioquímica e minha irmã Natalia veio a ser geneticista. Perceberam, no entanto, que nenhuma quantidade de pesquisa poderia curar as doenças sistêmicas da sociedade soviética e da sua economia em geral, bem como do sistema médico em particular. Em casa, ouvi histórias terríveis a respeito de uma enfermeira que não esterilizava agulhas e seringas reutilizáveis (as descartáveis somente se tornaram disponíveis na Rússia de hoje, após a queda do "Império do Mal") antes de utilizá-las novamente em outros pacientes. Outra história dizia respeito a um socialista devotado, que se recusava a pagar 
propinas e que morreu tentando chegar ao banheiro após uma cirurgia cerebral.

Em outro caso, testemunhei como o irmão de meu melhor amigo, Vladimir, engenheiro de aeronaves, foi roubado e severamente espancado em Moscou. Foi encontrado caído na rua por um oficial de polícia e levado a um hospital de emergência, onde foi diagnosticado com uma fratura do crânio basilar, região que divide o crânio nos segmentos anterior e posterior ${ }^{2}$. Seus médicos me garantiram que fariam tudo para ajudar em sua recuperação, acrescentando que esperavam receber uma compensação, observando que esse tipo de ferimento apresentava uma alta taxa de mortalidade e que se, Deus queira que não, algo viesse a lhe acontecer, ninguém investigaria a respeito de uma morte em uma situação que apresentava taxa de mortalidade elevada. Diante dessa ameaça de morte dissimulada, sua família pagou uma polpuda propina.

Não posso esquecer da filha de meu vizinho, uma graciosa e reluzente menina de 14 anos, que morreu de nefrite aguda após um diagnóstico equivocado de dor neuropática. Erro que teria sido facilmente evitado mediante um exame de raio- $\mathrm{X}$. O hospital, no entanto, estava sem filme de raio-X, e a criança morreu por causa disso. Os pais da menina, tal como todos os demais cidadãos soviéticos, não contavam com nenhuma solução legal e seus avós morreram de tristeza logo depois. $\mathrm{O}$ médico não recebeu nenhuma advertência - não era por sua culpa que "não havia filme". $O$ filme de raio- $X$ necessário estava estocado e vencendo, em abundância, nos hospitais do Partido.

Nos anos de 1987 a 1989, como Deputado do Povo na região de Moscou, recebi muitas reclamações a respeito de negligência criminosa, subornos recebidos por pessoas das equipes médicas e motoristas de ambulância

\footnotetext{
${ }^{2}$ WikiAnswers. Hingefractureofskullisseeninaccidents envolving? Answers.com. Disponível em: <http://wiki. answers.com/Q/Hinge_fracture_of_skull_is_seen_in_ accidents_involving.AccessedMay42011.3>.
}

bêbados. Li relatórios policiais a respeito de pacientes sendo roubados pelo pessoal das ambulâncias e pelos funcionários das salas de emergência. Muitas instalações - especialmente nas áreas rurais - eram imundas, infestadas de ratos e baratas, desprovidas de sabão e material de limpeza, produzindo assim um clima geral de desesperança. De acordo com os dados confidenciais aos quais tive acesso ao trabalhar para o governo em Moscou, $78 \%$ de todas as vítimas de AIDS da Rússia contraíram a doença de agulhas contaminadas ou de sangue infestado nos hospitais do Estado.

\section{IV - Estatísticas Enganadoras: Mortalidade Infantil, Cuidados Maternos e Expectativa de Vida}

Danos uterinos são comuns entre as mulheres russas devido a uma média de 7.3 abortos por mulher em idade fértil. $\mathrm{O}$ aborto é eficiente em custos para o sistema médico socializado, dado que elimina a necessidade de proporcionar cuidados médicos a bebês e crianças. Também reflete uma falta de fé no futuro por parte das mulheres, que abortam seus filhos. Quando os bebês nascem, a taxa de mortalidade infantil é muito alta, em algumas regiões tão alta quanto as taxas na Angola e Somália. Dizem que os Estados Unidos apresentam uma alta taxa de mortalidade infantil. Entretanto, nos Estados Unidos, todos os nascimentos, em qualquer idade gestacional, com qualquer tipo de pulsação no cordão umbilical, ou com qualquer respiração espontânea, são contados como nascimentos vivos, enquanto várias nações socialistas só contam os bebês como nascimentos vivos quando já têm dias, ou mesmo meses de idade.

Mesmo atualmente, de acordo com o Comitê de Estatísticas do Estado Russo, a expectativa de vida média para os homens russos fica abaixo de 59 anos e, para as 
mulheres, fica em 72 anos $^{3}$. Enquanto isso, nos Estados Unidos, os números correspondentes são 73 anos para homens e 79 anos para mulheres ${ }^{4}$. Em geral, o experimento socialista na União Soviética, China, Coreia do Norte, Cuba e outros países socialistas de linha dura provocou sofrimento e mortes em massa, devido à falta de saneamento e de cuidados médicos. Após 74 anos de socialismo, 57\% dos hospitais na Rússia não têm água quente e 36\% não contam com instalações de água ou esgoto.

Há, também, toneladas de evidências ${ }^{5}$ de que os prisioneiros nos Gulags eram usados como cobaias pelos "pesquisadores médicos" do KGB. Todas estas "pesquisas" terminariam com o assassinato dessas cobaias, dado que as autoridades não correriam o risco de deixar para trás testemunhas de seus crimes.

\section{V - A Medicina Socialista Provocou Retrocessos na Qualidade dos Cuidados Médicos Inclusive em Nações Desenvolvidas no Ocidente}

O declínio na qualidade dos serviços médicos ocorreu mesmo em sociedades ocidentais avançadas. É resultado direto do monopólio do governo e ocorrerá em qualquer país onde a medicina socializada venha a ser implementada. Por exemplo, na Inglaterra, 800.000 pessoas esperam na lista por uma cirurgia, de uma população total de 55 milhões. Os hospitais britânicos não contam com equipamentos de ponta. Somente $10 \%$ dos gastos médicos são privados. A despeito de terem sido pioneiros no desenvolvimento da diálise renal, a Grã-Bretanha apresenta uma das menores taxas de diálise do mundo.

${ }^{3}$ TITOVA, I. Russian life expectancy on downward trend. St. Petersburg Times (Jan 17, 2003).

${ }^{4}$ SHRESTHA, L. B. Life Expectancy in the United States. CRS Report for Congress. Order Code RL32792. Washington, D.C.: Congressional Research Service.

${ }^{5}$ SNORE, E. The Soviet Story. DVD. Latvia, 2008.
Pacientes suecos frequentemente reclamam a respeito das listas de espera - recentemente, o governo introduziu uma garantia de espera de seis meses ${ }^{6}$. Há pouco tempo, os suecos começaram a se inclinar mais na direção da privatização dos serviços médicos.

\section{VI - Propaganda nos Estados Unidos DA AMÉRICA}

Nos Estados Unidos da América, defensores do socialismo que pressionam por cuidados médicos gerenciados pelo Estado utilizam a NPR e o PBS para doutrinar americanos e fazer com que acreditem que seus cuidados médicos não são os melhores do mundo. Para isso, utilizam seu próprio dinheiro dos impostos, chamando a rádio e televisão do governo de "bens públicos". A mensagem socialista também é promulgada sem subsídio de impostos pela $\mathrm{ABC}, \mathrm{NBC}, \mathrm{MSNBC}, \mathrm{CBS}, \mathrm{CNN}$ e pela maior parte das emissoras locais da Fox. Esses socialistas norte-americanos reproduzem os passos empregados pelos soviéticos para fazer propaganda aos russos. Michael Moore é um dos principais exemplos, comparando de maneira desfavorável e equivocada nossos cuidados médicos dos pacientes mais velhos, que apresentam doenças sérias e complexas, com os cuidados médicos na França de mulheres jovens que passam pela gravidez sem complicações. Caso tivesse feito o contrário - comparado os cuidados médicos das jovens grávidas nos Estados Unidos da América com os cuidados proporcionados aos pacientes mais velhos com doenças sérias e complexas na França, Reino Unido e

${ }^{6}$ TRIGGLE, N. How the NHS could learn from Sweden [news release]. BBC (Nov 28, 2005). Disponível em: $<$ http://news.bbc.co.uk/2/hi/health/4460098.stm>.

7 GLENNGARD, A. H. ; HJALTE, F. ; SVENSSON, M. ; ANELL, A. \& BANKAUSKAITE, V. Health Systems in Transition. Copenhagen, Denmark: WHO Regional Office for Europe, on behalf of the European Observatory on Health Systems and Policies, 2005: 103. Disponível em: <www.euro.who.int/_data/assets/ pdf_file/0010/96409/E88669.pdf $>$. 
Canadá -, seu filme Sicko teria feito com que os serviços médicos norte-americanos parecessem ser os ideais, enquanto os cuidados médicos na França, Reino Unido e Canadá pareceriam atrasados e desumanos.

\section{VII - DisCRIMINAÇÃo EtáRIA NA Medicina Socializada}

A discriminação etária é bastante visível nos sistemas médicos conduzidos pelo Estado ou fortemente regulados. Nos Estados Unidos da América, isso ainda não tem acontecido porque os mais velhos representam boa parcela dos eleitores. Na Rússia, contudo, pacientes com mais de 60 anos eram considerados parasitas inúteis e os que tinham mais de 70 anos geralmente não tinham acesso mesmo a tratamentos rotineiros, a menos que fossem membros da elite. Vários exemplos deste tipo de tratamento, no qual alguns são mais iguais e mais merecedores do que outros, ocorrem em nações onde os serviços médicos são socializados.

Atualmente, nos Estados Unidos da América, estamos sendo insidiosamente preparados para a discriminação etária no tratamento médico dos mais velhos, que já consomem muitos recursos. O Dr. Ezekiel Emanuel é diretor do Departamento de Bioética Clínica no Instituto Nacional de Saúde e é um dos arquitetos que contribuíram para a formulação do projeto de saúde ObamaCare. Também é irmão de Rahm Emanuel, o antigo chefe da equipe do Obama e atual prefeito de Chicago. Foster Friess relata que o Dr. Emanuel escreveu que os serviços de saúde não deveriam ser garantidos a indivíduos que, de maneira irreversível, não podem se tornar cidadãos "participantes". Um exemplo óbvio é a negação de cuidados médicos a pessoas com demência ${ }^{8,9}$.

${ }^{8}$ FRIESS, Foster. Can you believe denying health care to people with dementia is being considered? (July 14, 2009). Disponível em: <www.fosterfriess.com/ transforming+america/healthcare/articles/20512/>

${ }^{9}$ EMANUEL, E. J. Where civic republicanism and deliberative democracy meet. Hasting Center Report, Vol. 26, No. 6 (1996): 12-14.
Um artigo igualmente inquietante, escrito em coautoria com o Dr. Emanuel, apareceu no periódico The Lancet em janeiro de 2009. Persed et al. escrevem que diferentemente da alocação estatal forçada dos cuidados médicos por sexo ou raça, a alocação por faixa etária não configura discriminação individual porque cada pessoa vive através de estágios distintos da vida e não em uma única idade. Mesmo se os indivíduos de 25 anos forem priorizados sobre os de 65 anos, todos os que agora têm 65 anos já tiveram 25 anos. Tratar os de 65 anos de forma distinta devido a estereótipos ou falsidades seria discriminação por idade, porém tratá-los de maneira diferente por já terem mais anos de vida não seria, de acordo com o artigo ${ }^{10}$. Com relação ao racionamento por faixa etária, a imagem que apresentam na página 6 de seu artigo conta a história toda. O título da imagem é "Prioridade de acesso a intervenções médicas escassas por faixa etária sob o Complete Lives System". Trata-se de um eufemismo para negar cuidados aos idosos.

É possível observar que a curva cai acentuadamente após a idade de 55 anos, o que significa que a probabilidade de receber uma intervenção médica depois dessa idade não é muito alta sob o "Complete Lives System". Persed et al. também mencionam, em seu artigo, a "justiça social" e defendem que a "utilidade social" de uma pessoa para a sociedade (conforme determinada por algum burocrata da elite governamental) deveria ser um fator ao decidir quem receberá e quem não receberá tratamento sob o sistema de racionamento "Complete Lives System".

Obviamente, as lições da história nos ensinam muito com relação ao que acontece àqueles que não são considerados "socialmente úteis". Os nazistas se referiam a eles como "inúteis comedores de pães". Joseph Stalin os chamava de "parasitas sociais", en-

${ }^{10}$ PERSAD, G. ; WERTHEIMER, A. \& EMANUEL, E. J. Principles for allocation of scarce medical interventions. Lancet, Vol. 373 (2009): 423-431. 
quanto matava de fome, sistematicamente, milhões de camponeses, intelectuais e outros indivíduos escolhidos ao acaso.

Economias reais em um sistema médico socializado somente podem ser obtidas negando cuidados e denegrindo médicos. Em um sistema de livre mercado, as pessoas estariam livres para escolher o que seria melhor para sua situação individual. Companhias de seguros, ao invés receberem dos burocratas instruções exatas do que deveriam apresentar em suas apólices, estariam livres para produzir apólices de acordo com os desejos das pessoas.

\section{VIII - Médicos com Síndrome de Estocolmo}

Alguns médicos norte-americanos que apoiam as propostas para uma medicina socializada são como gado atraído por forragem em direção ao abatedouro. Não entendem a economia dos cuidados médicos nos Estados Unidos da América, tampouco entendem a natureza econômica geral do socialismo, inclusive das regulações governamentais, que consomem um custo elevado para nenhum benefício - regulações que também impedem a competição que diminuiria os custos. Esses médicos também não entendem que seus pacientes serão como gado em uma fazenda do governo e que eles próprios serão peões desse mesmo governo, meras peças de mão-de-obra.

Uma maior intromissão do governo e regulamentação excessiva da medicina não resolverá o problema. Pelo contrário, deverá agravá-lo. Enquanto isso, esses médicos socialistas não são capazes de reconhecer que a razão pela qual desfrutam de algumas das rendas mais altas do mundo é justamente não estarem sujeitos a um sistema controlado pelo governo, com seus controles de preços e restrições sobre a renda recebida (como os "clawbacks" - cláusulas de regresso - no Canadá).

Regulações impostas pelo governo, tais como "certificados de necessidade", licenciamentos e outras restrições sobre a disponibilidade dos serviços médicos evitam a concorrência e, portanto, resultam em preços mais elevados e menos serviços.

\section{IX - ObamaCare: Uma Repetição do Pesadelo Socialista}

O "ObamaCare" resultará na criação de grandes burocracias governamentais, que não produzirão nada de valor, mas que estrangularão ainda mais a medicina norteamericana. Introduzirá à força mandatos onerosos e destruidores de empregos sobre os empregadores, para que forneçam a cobertura do tipo que o governo estabelece que as pessoas devem ter. Isso resultará em racionamentos não baseados em preços, isto é, fundamentados em considerações políticas, corrupção e discriminação. Haverá escassez, listas de espera e cuidados médicos de baixa qualidade proporcionados por escravos do sistema, tal como ocorria no sistema do qual saí.

\section{X - Norte-Americanos Querem Reformas, e Não Socialismo}

O eminente economista Hans-Hermann Hoppe escreveu em 1993: "Está na hora de tratarmos seriamente o tema da reforma de saúde. Créditos fiscais, vouchers e a privatizaçãopercorrerão um longo caminho para descentralizar o sistema e remover fardos desnecessários do negócio". Sua proposta, "Uma Solução para a Saúde em Quatro Passos", faz bastante sentido para a criação de um mercado livre e eficiente para os cuidados de saúde. Esses passos incluem:

1. Eliminar todas as exigências de licenciamento para as faculdades de medicina, hospitais, farmácias, médicos e outros profissionais da saúde. A oferta destes itens aumentaria imediatamente, os preços cairiam e uma maior variedade de serviços de saúde apareceria no mercado.

Agências de credenciamento, competindo voluntariamente no mercado, substituiriam 
o licenciamento compulsório do governo considerando que os fornecedores de serviços de saúde (afinal de contas, serviços de saúde são serviços como quaisquer outros) acreditem que esse reconhecimento melhoraria sua reputação e que seus consumidores, por se importarem com a reputação dos fornecedores, serão propensos a pagar por isso.

Como os consumidores não mais seriam enganados para acreditar que existe um "padrão nacional" de saúde, aumentariam sua procura por bons serviços de saúde a custos baixos e fariam escolhas mais sábias.

2. Eliminar todas as restrições governamentais sobre a produção e a venda de produtos farmacêuticos e equipamentos médicos. Isso implica na extinção das agências reguladoras encarregadas de controlar remédios, vacinas, drogas e produtos biológicos. Atualmente, essas agências servem apenas para obstruir inovações e elevar os custos de produção.

Custos e preços cairiam, e uma maior variedade de produtos melhores chegaria ao mercado com mais celeridade. $\mathrm{O}$ mercado também forçaria os consumidores a agirem de acordo com suas próprias avaliações de risco, ao invés de confiar essa tarefa ao governo. Fabricantes e vendedores de remédios e aparelhos, devido à concorrência, teriam de fornecer cada vez mais garantias e descrições melhores de seus produtos, tanto para evitar processos por produtos defeituosos, quanto para atrair mais consumidores.

3. Desregulamentar a indústria de seguros de saúde. A iniciativa privada pode oferecer seguros contra eventos cuja ocorrência fica fora do controle do segurado. Por outro lado, uma pessoa não pode fazer um seguro, por exemplo, contra o suicídio ou a falência, pois depende apenas dessa pessoa fazer com que tais eventos ocorram.

Como a saúde de uma pessoa, ou sua falta, depende quase exclusivamente desta pessoa, muitos dos riscos de saúde (se não a maior parte) não são, efetivamente, seguráveis. Um "seguro" contra riscos cuja probabilidade de ocorrer pode ser sistematicamente influenciada por um indivíduo depende fortemente da própria responsabilidade desta pessoa.

Além do mais, qualquer tipo de seguro envolve compartilhamento de riscos individu- ais. Isso significa que as seguradoras paguem mais para alguns e menos para outros. No entanto, ninguém sabe com antecedência, e com convicção, quem serão os "ganhadores" e quem serão os "perdedores". "Ganhadores" e "perdedores" são distribuídos de forma aleatória e a distribuição de renda resultante não é nem um pouco metódica. Se "ganhadores" e "perdedores" pudessem ser determinados de forma sistemática, os "perdedores" não desejariam compartilhar seus riscos com os "ganhadores", mas sim com outros "perdedores", porque isso diminuiria seus custos. Por exemplo, eu não desejaria compartilhar meu risco de sofrer acidentes pessoais com os riscos incorridos por jogadores profissionais de futebol; compartilharia meus riscos exclusivamente com os riscos de pessoas em circunstâncias semelhantes às minhas, a custos mais baixos.

Devido às restrições legais impostas sobre as seguradoras de saúde, que não têm o direito de recusar certos serviços - excluir algum risco individual por este não ser segurável, por exemplo -, o atual sistema de saúde tem preocupação apenas parcial de assegurar. A indústria de seguros não pode discriminar livremente entre os diferentes riscos incorridos por diferentes grupos.

Como resultado, as seguradoras de saúde precisam cobrir uma multidão de riscos não seguráveis juntamente com riscos que são genuinamente seguráveis. Não podem discriminar os vários grupos de pessoas que apresentam riscos de seguridade significativamente diferentes. Assim, a indústria de seguros termina por gerenciar um sistema de redistribuição de renda - beneficiando agentes irresponsáveis e grupos de alto risco às custas de indivíduos responsáveis e dos grupos de baixo risco. Logicamente, os preços desta indústria se encontram altos e em elevação constante.

Desregulamentar esta indústria significa devolver-lhe liberdade de contrato irrestrita: permitir que uma seguradora de saúde seja livre para oferecer qualquer tipo de contrato, para incluir ou excluir qualquer tipo de risco e para discriminar quaisquer tipos de grupos ou de indivíduos. Riscos não seguráveis perderiam a cobertura, a variedade de políticas de seguridade para as coberturas remanes- 
centes sofreria um aumento e as diferenças de preços refletiriam os riscos reais de cada seguro. Em termos gerais, os preços cairiam de maneira drástica. Tal reforma restauraria a responsabilidade individual na saúde.

4. Eliminar todos os subsídios para os enfermos. Os subsídios sempre criam mais daquilo que é subsidiado. Subsídios para enfermos alimentam a doença e a enfermidade, bem como promovem o descuido, a indigência e a dependência. Se estes subsídios forem eliminados, fortalecer-se-ia a intenção de levar uma vida saudável e de trabalhar para o próprio sustento. Inicialmente, isso significa abolir todos os tipos de tratamento e assistência médica "gratuitos" - ou seja, financiados compulsoriamente pelos contribuintes saudáveis e zelosos de sua saúde.

Apenas essas quatro medidas, embora drásticas, poderão restaurar um livre-mercado completo no fornecimento de serviços médicos. Enquanto estas medidas não forem adotadas, a indústria continuará enfrentando sérios problemas - que afetam de maneira extremamente negativa a vida de seus consumidores ${ }^{11}$.

Sistemas médicos socializados não conseguiram aumentar a saúde geral ou elevar os padrões de vida em parte alguma. Na verdade, tanto o raciocínio analítico quanto as evidências empíricas apontam na direção da conclusão oposta. No entanto, o lúgubre fracasso da medicina socializada em aumentar a saúde e a longevidade das pessoas infelizmente não impactou em seu apelo para certos políticos, administradores e seus servos intelectuais em sua busca pelo poder absoluto e controle total. Defensores do sistema de saúde socializado insistem que é um tema "muito importante" para ser deixado ao sabor dos caprichos do mercado. Don Boudreaux, na grande tradição do economista e filósofo francês Frédéric Bastiat (1801-1850), escreveu um ensaio maravilhosamente divertido, "A Escola do Supermercado".

11 HOPPE, Hans-Hermann. A four-step health-care solution. Mises Daily (Aug 14, 2009). Disponível em: $\quad<$ https://mises.org/library/four-step-healthcaresolution $>$.
Insiste em que os supermercados também são muito importantes e discute os possíveis resultados da socialização do fornecimento de alimentos $^{12}$.

A maior parte dos países escravizados pelo império soviético abandonou o sistema completamente socializado por meio da privatização e garantindo a concorrência no sistema médico. Outros, inclusive diversas socialdemocracias europeias, pretendem privatizar seus sistemas médicos no longo prazo e descentralizar o controle sobre a medicina. A propriedade privada dos hospitais e de outras unidades é considerada um fator determinante crítico para um sistema novo, mais eficiente e mais humano.

Um membro do Parlamento russo, Oleg Kulikov, sintetizou esta tendência para a privatização da seguinte maneira:

É fascinante: estamos voltando ao capitalismo nos cuidados de saúde ao aumentar a parcela de pagamentos privados e provisão de serviços de saúde, enquanto Obama sugere um sistema que podemos corretamente definir como comunista ou socialista. Estão assumindo posições que abandonamos ${ }^{13}$.

Um herói da medicina canadense, o Dr. Jacques Chaoulli, processou o governo de Quebec argumentando que a implementação canadense de um sistema de saúde com financiamento público não é eficiente para proporcionar um nível de cuidados de saúde que seja adequado. A decisão da Suprema Corte Canadense para esse caso resultou em uma mudança na política do governo de Quebec a respeito dos tempos de espera e abriu a possibilidade de privatização desses cuidados. "Desafiar um poderoso monopólio estatal sobre os serviços médicos não é fácil, porém atingi o ponto que não podia mais tolerar ao ver

12 BOUDREAUX, D. Grocery school. Café Hayek (Apr 24, 2001). Disponível em: <http://cafehayek. com/2011/04/grocery-school.html>.

${ }^{13}$ KULIKOV, O. Obama's system of mandatory health insurance is a copy of Soviet public health system. Our government's proposed reform is capitalist. Proceedings, Russian State Duma, 2010. 
meus pacientes sofrerem e morrerem nas listas de espera, então tive que fazer algo", escreveu o Dr. Chaoulli ${ }^{14}$.

De acordo com o European Journal of Public Health:

Ideias a respeito da privatização do sistema de saúde na Europa Ocidental foram impulsionadas pela crise do sistema de bemestar social, por um desejo de mais eficiência e pelo exemplo dos negócios privados como modelos para a otimização do fornecimento de serviços. Historicamente, as experiências negativas, que abriram o caminho para a privatização, foram a rigidez das instituições públicas e sua incapacidade para mudar ou se adaptar aos diferentes estímulos de seu ambiente, inclusive as expectativas da população e dos pacientes ${ }^{15}$.

A privatização, em oposição à socialização, é a resposta para nossos problemas de financiamento e provisão de serviços médicos. "Foi demonstrado que vale a pena, pois elimina o desperdício, poupa recursos, reduz déficits orçamentários e a dívida do governo, e cria um sistema de saúde melhor para os mais necessitados ${ }^{16^{\prime \prime}}$.

\footnotetext{
${ }^{14}$ CHAOULLI, J. The long road to freedom in Canadian
} medicine. J. Am. Phys. Surg., Vol. 10 (2005): 91-92.

${ }^{15}$ ALBRECHT, T. Privatization processes in health care in Europe - a move in the right direction, a "trendy" option, or a step back? Eur. J. Pub. Health, Vol. 19 (2009): 448-450.

16 WOOTTON, I. Privatisation in the healthcare industry. AEMH Conference, Brussels (May 7, 2009).
Doug French, do Instituto Ludwig von Mises, escreveu: “O socialismo médico não passa de uma variedade de um problema maior. No entanto, é particularmente devastador para as pessoas, pois afeta sua capacidade de se manterem saudáveis e vivas ${ }^{17 " . ~ A ~ u ́ l t i m a ~ l i n h a ~}$ de defesa para nossa liberdade, atualmente, é a luta contra esta tentativa ultrajante de nos transformar em peões do sistema de saúde socialista do governo. cos
${ }^{17}$ FRENCH, D. Healthcare intervention: the bigger picture. Mises Daily (Mar 24, 2010). Disponível em: $<$ https://mises.org/library/healthcare-interventionbigger-picture>. 